\title{
Destanização e conservação de frutos de jambolão
}

\author{
Detannization and conservation of Jambolan fruit
}

\author{
Joseana Severo $^{\mathrm{I}^{*}}$ Railson Schreinert dos Santos ${ }^{\mathrm{I}}$ Jardel Casaril $^{\mathrm{I}}$ Aline Tiecher $^{\mathrm{I}}$ \\ Jorge Adolfo Silva ${ }^{I}$ Cesar Valmor Rombaldi ${ }^{\mathrm{I}}$
}

\section{RESUMO}

\begin{abstract}
Foram estudadas alternativas para a redução da adstringência (destanização) e conservação de frutos de jambolão (Syzygium cumini, L.). Para isso, no primeiro experimento, os frutos foram colhidos no estádio meio-maduro, mantidos sob temperatura ambiente e submetidos aos seguintes tratamentos: controle (atmosfera normal), $98 \mathrm{kPa} \mathrm{CO}, 20 \mathrm{kPa}$ $\mathrm{CO}_{2}, 98 \mathrm{kPa} \mathrm{N}$, etileno (100ppm), 1-MCP (1 ppm) seguido de etileno (100ppm) e $3,85 \mathrm{~mL}$ de etanol absoluto $L^{-1}$. Foram avaliados os teores de acetaldeído e de taninos solúveis, a firmeza e a adstringência dos frutos. No segundo experimento, os frutos foram colhidos no estádio maduro e armazenados em atmosfera modificada passiva, sob temperatura ambiente (AMPA, $23 \pm 1^{\circ} \mathrm{C}$ ) e atmosfera modificada passiva refrigerada (AMPR, $\left.4 \pm 1^{\circ} \mathrm{C}\right)$, pelo período de cinco, 10 e 15 dias. Frutos provenientes dos tratamentos com $N_{2}$, etileno e etanol apresentaram os melhores resultados quanto à destanização, com aumento nos teores de acetaldeído e diminuição dos taninos solúveis e da adstringência; entretanto, os tratamentos com etileno e etanol causaram amolecimento excessivo nos frutos. O armazenamento em AMPR conservou melhor a coloração roxo-azulada dos frutos e, além de prevenir a incidência de fungos, auxiliou na manutenção dos teores de fenóis totais e de ácido ascórbico e na atividade antioxidante dos frutos.
\end{abstract}

Palavras-chave: taninos solúveis, pós-colheita, armazenagem.

\section{ABSTRACT}

Alternative methods were investigated for the reduction of astringency (detannization) and conservation of Jambolan fruit (Syzygium cumini, L.). In the first experiment, fruits were harvested at an intermediate ripening stage, maintained at room temperature and subjected to the following treatments: control (normal atmosphere), $98 \mathrm{kPa} \mathrm{CO}, 20 \mathrm{kPa}$ $\mathrm{CO}_{2}, 98 \mathrm{kPa} \mathrm{N}$, ethylene (100ppm), 1-MCP (1ppm) followed by treatment with ethylene (100ppm) and 3,85mL absolute ethanol $L^{-1}$. Acetaldehyde, soluble tannin, fruit firmness and astringency were evaluated. In the second experiment, fruits were harvested ripe and stored under passive modified atmosphere at room temperature (PMART, $23 \pm 1^{\circ} \mathrm{C}$ ) and passive modified atmosphere under cold storage (PMACS, $4 \pm 1^{\circ} \mathrm{C}$ ) for 5, 10 and 15 days. Fruits treated with $N_{2}$, ethylene and ethanol showed the best detannization results, with increased acetaldehyde content, reduction of soluble tannins and astringency. However ethylene and ethanol treatments induced excessive softening of the fruit. Storage under PMAR kept the purple-blue color of fruits and, besides preventing fungal incidence, it aided the maintenance of the total phenolic content, ascorbic acid and antioxidant activity of fruits.

Key words: soluble tannins, post-harvest, storage.

\section{INTRODUÇÃO}

Jambolão (Syzygium cumini, L), originário do sudeste Asiático, produz frutos pequenos, de forma ovoide e coloração que varia do verde, quando imaturo, ao roxo-azulado, quando maduro. A polpa, também roxa, é carnosa, com sabor ácido/doce e adstringência variável em função do estádio de maturação. Vários trabalhos, utilizando diferentes partes da planta, como folhas, casca, sementes e fruto, demonstram os efeitos benéficos do jambolão, com destaque para o potencial antimicrobiano, o diurético, o anti-hipertensivo e, principalmente, para a redução de glicemia em casos de diabetes melitus (GROVER et al., 2002).

'Departamento de Ciência e Tecnologia Agroindustrial (DCTA), Faculdade de Agronomia Eliseu Maciel (FAEM), Universidade Federal de Pelotas (UFPel), CP 354, 96010-900, Pelotas, RS, Brasil. E-mail: josi_severo@yahoo.com.br. *Autor para correspondência. 
Entre as potenciais propriedades medicinais do jambolão, a maioria está correlacionada à atividade antioxidante, que é citada como decorrente da presença de compostos fenólicos já identificados, como é o caso de ácidos fenólicos, como o ácido elágico, os flavonoides, como a quercitina e a rutina, e antocianinas, como a delfinidina-3-glicosídeo, a petunidina-3glicosídeo e a malvidina-3-glicosídeo (LIMA et al., 2007; VEIGAS et al., 2007; REYNERTSON et al., 2008).

Além da potencialidade de uso como produto fitoterápico, os frutos de jambolão apresentam potencial para o consumo in natura, por possuírem boa aparência e sabor agradável quando colhidos completamente maduros, pois, caso contrário, apresentarão elevada adstringência (VIZZOTO \& PEREIRA, 2008).

Desse modo, a otimização de métodos visando à redução da adstringência pode contribuir para o melhor aproveitamento desses frutos, seja na forma in natura, seja na forma processada. Um dos frutos modelo para esse tipo de estudo é o caqui (ANTONIOLLI et al., 2000), no qual foi verificado que o principio básico para a redução da concentração de taninos solúveis está baseado na indução da síntese de acetaldeído, que pode ser obtida pela diminuição de $\mathrm{O}_{2}$, pelo aumento de $\mathrm{CO}_{2}$ e/ou $\mathrm{N}_{2}$ ou pela aplicação de etanol (ANTONIOLLI et al., 2000; EDAGI \& KLUGE, 2009).

Nesse contexto, acredita-se que a utilização de métodos que provoquem a síntese de acetaldeído ou a solubilização de parede celular favoreçam a polimerização de taninos e, consequentemente, a redução da adstringência. Além disso, acredita-se que o uso da refrigeração, associada à atmosfera modificada passiva (AMP), possibilite o prolongamento da vida de prateleira dos frutos, auxiliando na preservação de suas propriedades antioxidantes. Para testar as hipóteses, foram estudados os efeito da hipoxia (aumento na concentração de $\mathrm{N}_{2}$ e $\mathrm{CO}_{2}$ ), do etileno e do etanol na redução da adstringência e o uso de AMPR na conservação de frutos de jambolão.

\section{MATERIAL E MÉTODOS}

Os frutos de jambolão foram colhidos na Região de Pelotas, Rio Grande do Sul (RS), no Centro Agropecuário da Palma da Universidade Federal de Pelotas (CAP/UFPEL), em árvores de 27 anos, no mês de abril de 2008. Para testar as hipóteses, dois experimentos foram realizados: 1) visando à redução da adstringência; e 2) visando ao prolongamento da conservação dos frutos.
Para o primeiro experimento, os frutos foram colhidos em estádio meio-maduro e acondicionados em frascos de vidro de 5,2L. Os tratamentos foram realizados em unidades experimentais de $200 \mathrm{~g}$, com três repetições, sendo testados controle (atmosfera normal), $98 \mathrm{kPa} \mathrm{CO}_{2}, 20 \mathrm{kPa} \mathrm{CO}_{2}, 98 \mathrm{kPa} \mathrm{N}_{2}, 100 \mathrm{ppm}$ de etileno e 1ppm 1-MCP seguido de 100ppm de etileno e $3,85 \mathrm{~mL}$ de etanol absoluto $\mathrm{L}^{-1}$. As condições de tratamento utilizadas foram definidas a partir de dados bibliográficos e de experimento exploratório, no qual foram testadas várias concentrações de $\mathrm{CO}_{2}(10,20,40$, 60 e $98 \mathrm{kpa})$, temperaturas $\left(15,23\right.$ e $\left.28^{\circ} \mathrm{C}\right)$ e tempos de tratamento $(12,24,36$ e $48 \mathrm{~h})$. A partir desse estudo prévio, verificou-se que os melhores resultados foram obtidos com o tratamento a $23^{\circ} \mathrm{C}$, por $24 \mathrm{~h}$. Concluído o período de $24 \mathrm{~h}$ de tratamento, os frutos foram retirados dos recipientes e mantidos durante $48 \mathrm{~h}$ em bandejas expostas à temperatura ambiente $\left(23 \pm 1^{\circ} \mathrm{C}\right)$. As avaliações foram realizadas no momento da instalação do experimento (0h), na retirada dos frutos dos recipientes (24h) e após $48 \mathrm{~h}$ sob temperatura ambiente. O teor de acetaldeído foi avaliado na instalação do experimento (0h) e após $24 \mathrm{~h}$ de exposição dos frutos aos tratamentos, por meio da coleta de $1 \mathrm{~mL}$ de ar do interior dos frascos, realizando a quantificação por cromatografia gasosa e expressando os resultados em

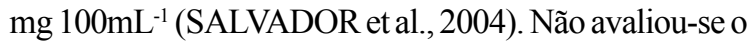
teor de acetaldeído após $48 \mathrm{~h}$ de aplicação dos tratamentos, pois os frutos já haviam sido retirados dos recipientes. O teor de taninos solúveis, a adstringência e a firmeza foram avaliados após $0,24 \mathrm{e}$ 48h de exposição à temperatura ambiente. $\mathrm{O}$ teor de taninos solúveis foi quantificado por espectrofotometria, com resultados expressos em g. $100 \mathrm{~g}^{-1}$ (ANTONIOLLI et al., 2000), já a firmeza foi avaliada pelo uso de texturômetro TA.XTplus ${ }^{\circledR}$, expressando os resultados em kgf, e a análise sensorial foi avaliada por meio de escala não estruturada, com dez provadores treinados, na qual o valor 0 representa ausência de adstringência, e o valor 9 representa fruto extremamente adstringente.

No segundo experimento, os frutos foram colhidos em estádio maduro e acondicionados em embalagens de poliestireno expandido (EPS), com capacidade média de $100 \mathrm{~g}$, cobertos com filme de policloreto de vinila (PVC) de 12ìm de espessura e armazenados em atmosfera modificada passiva à temperatura ambiente (AMPA, $23 \pm 1^{\circ} \mathrm{C}$ ) e atmosfera modificada passiva refrigerada (AMPR, $4 \pm 1^{\circ} \mathrm{C}$ ), sem controle de umidade relativa. As avaliações foram realizadas nos períodos de cinco, 10 e 15 dias de armazenamento. Para cada tratamento, em cada período de avaliação, foram preparadas três unidades 
experimentais, cada uma representada por uma embalagem com $100 \mathrm{~g}$ de frutos. O teor de sólidos solúveis (SS) e o teor de acidez titulável (AT) foram avaliados de acordo com as normas do INSTITUTO ADOLFO LUTZ (1985). A coloração dos frutos foi avaliada com o emprego de colorímetro Minolta CR 300, padrão CIE-Lab, sendo expressa pelo ângulo Hue $\left(\mathrm{h}^{\circ}=\operatorname{tang}^{-1} \mathrm{~b}^{*} \cdot \mathrm{a}^{*-1}\right)$. A incidência de podridões foi avaliada de acordo com MALGARIM et al. (2006). Os compostos fenólicos totais foram quantificados por espectrofotômetria, sendo utilizada curva-padrão do ácido gálico e expressos os resultados em mg EAG $100 \mathrm{~g}^{-1}$ (SINGLETON \& ROSSI, 1965). O teor de antocianinas totais foi determinado por espectrofotometria, sendo utilizada curva-padrão da cianidina-3-glicosídio e expressos os resultados em $\mathrm{mg}$ EqCianidina3-glic $100 \mathrm{~g}^{-1}$ (LEES \& FRANCIS, 1972). O ácido ascórbico foi quantificado por meio de cromatografia líquida de alta eficiência (HPLC), sendo os resultados expressos em mg $100 \mathrm{~g}^{-1}$ (VINCI et al., 1995). A atividade antioxidante foi determinada por espectrofotometria a partir do radical ABTS (2,2'azinobis-3-etilbenzotiazolin 6-ácido sulfônico), sendo utilizada curva-padrão com o Trolox (ácido 6-Hidroxi2,5,7,8-tetrametilcroman-2-carboxilico) e os resultados expressos em ìmol g-1 (RE et al., 1999).
Em ambos os experimentos, o delineamento foi inteiramente casualizado, com três repetições biológicas, cada uma com três repetições da análise. Os dados foram submetidos à análise de variância, sendo aplicado o teste F. No primeiro experimento, as respostas dos tratamentos foram comparadas pelo teste de Tukey, com nível de 5\% de significância, e os valores dos intervalos de confiança foram plotados nos gráficos, mostrando as diferenças significativas entre as médias dos tratamentos (SigmaPlot ${ }^{\circledR}$ 9.0). Para o segundo experimento, os efeitos do método e dos dias de armazenamento foram avaliados pelo teste de Tukey, com nível de 5\% de significância.

\section{RESULTADOS E DISCUSSÃO}

Experimento I - Efeito do $\mathrm{CO}_{2}, \mathrm{~N}_{2}$, etileno e etanol na redução da adstringência

Os tratamentos que empregaram o $\mathrm{CO}_{2}$, na concentração parcial de $98 \mathrm{kPa}$ e $20 \mathrm{kPa}$, não foram eficientes no aumento dos teores de acetaldeído e na redução de taninos solúveis e da adstringência (Figura 1). É conhecido que o incremento da concentração de $\mathrm{CO}_{2}$ contribui para a polimerização de taninos em caquis (EDAGI \& KLUGE, 2009). Entretanto, em jambolão, esse comportamento não foi observado. Nos tratamentos
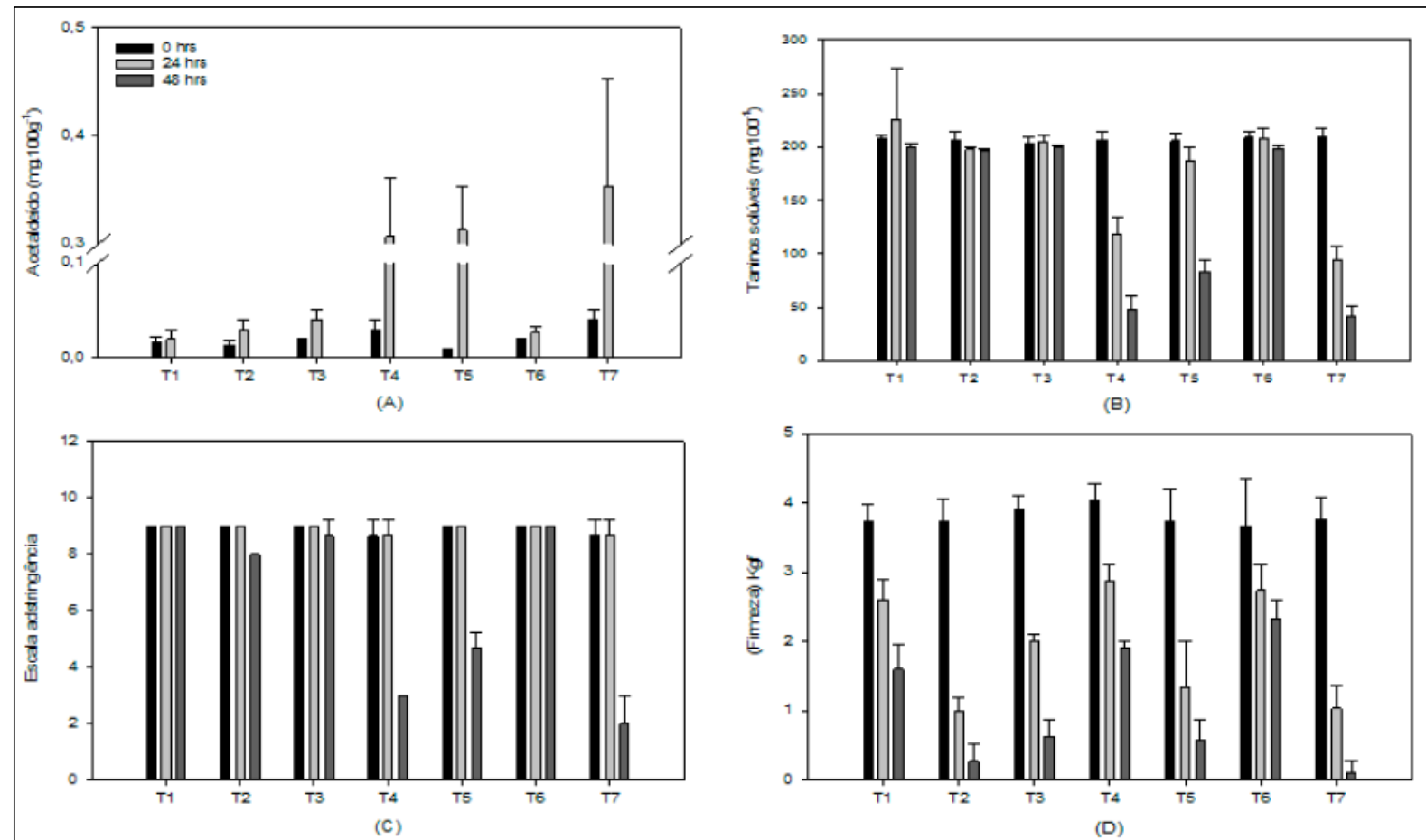

Figura 1 - Teores de acetaldeído (A), taninos solúveis (B), adstringência (C) e firmeza (D) em frutos de jambolão submetidos aos tratamentos: Temperatura ambiente (T1-controle), 98kPa de $\mathrm{CO}_{2}(\mathrm{~T} 2), 20 \mathrm{kPa}$ de $\mathrm{CO}_{2}(\mathrm{~T} 3), 98 \mathrm{kPa}$ de $\mathrm{N}_{2}(\mathrm{~T} 4), 100 \mathrm{ppm}$ de etilenon (T5), $1 \mathrm{ppm}$ de 1-MCP seguido de 100ppm de etileno (T6) e 3,85mL de etanol absoluto $\mathrm{L}^{-1}$ (T7). Barras verticais indicam intervalo de confiança de $5 \%$. 
com $\mathrm{CO}_{2}$, as médias das notas obtidas foram de 8 e 7 , respectivamente, para 98 e $20 \mathrm{kPa}$ (Figura 1C), indicando elevada adstringência dos frutos mesmo após esses tratamentos. As razões pelas quais os jambolões não responderam de forma similar ao observado em caquis não foram elucidadas, mas podem ser explicadas pelas variações de tipos de taninos existentes entre as duas espécies, já que o mecanismo bioquímico de complexação dos taninos em frutos submetidos à condição de anoxia é baseado na descarboxilação do piruvato, gerando etanol e acetaldeído, esse último envolvido na polimerização de taninos (SALVADOR et al., 2008).

A redução da concentração de $\mathrm{O}_{2}$, devido o uso de $\mathrm{N}_{2}$, proporcionou aumento no teor de acetaldeído, diminuição nos teores de taninos solúveis e da adstringência, além de melhores resultados em relação à manutenção da firmeza dos frutos (Figura 1). $\mathrm{O}$ aumento da concentração de $\mathrm{N}_{2}$ para pressões parciais de $98 \mathrm{kPa}$ é capaz de criar condições de metabolismo anaeróbio, induzindo a via glicolítica, com síntese de acetaldeído, conhecido como acelerador da polimerização de taninos, e inclusive complexação de taninos e compostos antociânicos (EDAGI \& KLUGE, 2009), o que explica a boa preservação da coloração e a redução da adstringência observadas neste trabalho (Tabela 1 e Figura 1C).

Uma possível participação do etileno no processo de destanização foi confirmada por meio dos tratamentos com etileno e 1-MCP seguido de etileno. No tratamento em que se aplicou somente o etileno, foi possível observar aumento no teor de acetaldeído, diminuição no teor de taninos solúveis e redução da adstringência; entretanto, a firmeza dos frutos diminuiu excessivamente (Figura 1). Embora se trate de fruto sem comportamento climatérico clássico, é possível confirmar a ação do etileno, pelo tratamento dos frutos com 1-MCP seguido de etileno, no qual, em razão da inibição da ação do etileno pelo 1-MCP, não foram observadas as mesmas respostas do tratamento somente com etileno.

No tratamento em que se aplicou etanol, foi possível observar significativo aumento no teor de acetaldeído, diminuição do teor de taninos solúveis e redução da adstringência. Entretanto, novamente, os frutos se apresentaram excessivo amolecimento (Figura 1). O efeito positivo do uso do etanol na redução do teor de taninos solúveis pode ser atribuído à ação de enzimas da família das álcool desidrogenases (ADHs), catalizadoras da bioconversão etanol em acetaldeído (ANTONIOLLI et al., 2000). A causa provável da perda de firmeza de polpa em frutos tratados com etileno e etanol pode estar associada à indução da síntese e atividade de enzimas pectolíticas, o que favoreceria, além do amolecimento, a redução do teor de taninos solúveis pela interação dessas moléculas com oligossacarídeos solubilizados da parede celular.

Experimento II - Conservação de frutos de jambolão em atmosfera modificada passiva à temperatura ambiente (AMPA) e atmosfera modificada passiva refrigerada $(A M P R)$

À medida que se estendeu o período de armazenamento, observou-se redução do teor de sólidos solúveis e da acidez tilulável dos frutos de jambolão, tanto em AMPA, como AMPR (Tabela 1). A redução dos teores de SS e de AT pode ser explicada pelo fato de que, com a respiração, há consumo de ácidos e açúcares, principais compostos das variáveis analisadas. No entanto, não houve efeito dos métodos de armazenamento sobre as variáveis SS e AT, pois se esperava que sob AMPR houvesse preservação dos teores de SS e AT, tendo em vista que a refrigeração e a modificação de atmosfera contribuem para a redução da taxa respiratória (CHITARRA \& CHITARRA, 2005). Nos frutos mantidos sob AMPR, não foi observada a incidência de podridões. Em frutos armazenados em AMPA, por sua vez, os primeiros sinais de podridões apareceram no $10^{\circ}$ dia, atingindo $55 \%$ dos frutos no $15^{\circ}$ dia de armazenamento (Tabela 1). Isso pode ser explicado pelo fato de que a associação de substrato ácido com elevada atividade de água, em temperaturas relativamente altas $\left(23^{\circ} \mathrm{C}\right)$, favorecem o crescimento de microrganismos, reduzindo a vida de prateleira dos frutos.

A AMPR foi eficiente na manutenção da coloração dos frutos, não havendo diferenças significativas das médias referentes ao ${ }^{\circ} \mathrm{Hue}$ no armazenamento. Já os frutos armazenados em AMPA apresentaram mudanças significativas nos valores de ${ }^{\circ}$ Hue, com a coloração tendendo à tonalidade avermelhada, na medida em que o armazenamento avançava (Tabela 1). A variação da coloração dos frutos armazenados em AMPA acompanhou o aumento nos teores de antocianinas totais (Tabela 1) e pode ser decorrente de modificações na estrutura das antocianinas, que, quando submetidas a temperaturas mais elevadas, podem sofrer reações de copigmentação, influenciando a coloração dos frutos de jambolão (VEIGAS et al., 2007).

O teor de compostos fenólicos decresceu durante o armazenamento, em maior intensidade nos frutos armazenados em AMPA (Tabela 1). A maior preservação do teor de fenóis totais em frutos mantidos em AMPR pode ser decorrente da menor oxidação desses compostos sob refrigeração. 
Tabela 1 - Teores de SS, AT, podridões, ${ }^{\circ}$ Hue, fenóis totais, antocianinas totais, ácido ascórbico e atividade antioxidante em frutos de jambolão armazenados durante 15 dias em atmosfera modificada passiva refrigerada (AMPR) e ambiente (AMPA).

\begin{tabular}{|c|c|c|c|}
\hline \multirow[b]{2}{*}{ Variáveis } & \multirow[b]{2}{*}{ Armazenamento (Dias) } & \multicolumn{2}{|c|}{ 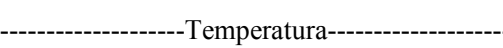 } \\
\hline & & AMPA & AMPR \\
\hline \multirow{4}{*}{ SS } & 0 & $17,50 \mathrm{aA}$ & $17,50 \mathrm{aA}$ \\
\hline & 5 & $17,50 \mathrm{aA}$ & $16,50 \mathrm{aA}$ \\
\hline & 10 & $16,87 \mathrm{aA}$ & $16,17 \mathrm{aA}$ \\
\hline & 15 & $12,48 \mathrm{bA}$ & $12,67 \mathrm{bA}$ \\
\hline \multirow{4}{*}{ AT } & 0 & $0,20 \mathrm{aA}$ & $0,20 \mathrm{aA}$ \\
\hline & 5 & $0,21 \mathrm{aA}$ & $0,20 \mathrm{aA}$ \\
\hline & 10 & $0,17 \mathrm{bA}$ & $0,17 \mathrm{bA}$ \\
\hline & 15 & $0,15 \mathrm{bA}$ & $0,15 \mathrm{bA}$ \\
\hline \multirow{4}{*}{ Podridões } & 0 & $0,00 \mathrm{aA}$ & $0,00 \mathrm{aA}$ \\
\hline & 5 & $0,00 \mathrm{aA}$ & $0,00 \mathrm{aA}$ \\
\hline & 10 & $23,33 \mathrm{bA}$ & $0,00 \mathrm{aB}$ \\
\hline & 15 & $55,00 \mathrm{cA}$ & $0,00 \mathrm{aB}$ \\
\hline \multirow{4}{*}{${ }^{\circ} \mathrm{Hue}$} & 0 & $428,70 \mathrm{aA}$ & $428,70 \mathrm{aA}$ \\
\hline & 5 & 340,41 aA & $333,09 \mathrm{aA}$ \\
\hline & 10 & $248,02 \mathrm{aA}$ & $331,77 \mathrm{aA}$ \\
\hline & 15 & $54,25 \mathrm{bA}$ & $339,09 \mathrm{aB}$ \\
\hline \multirow{4}{*}{$\begin{array}{l}\text { Fenóis Totais } \\
\left(\mathrm{mg} \text { EAG } 100 \mathrm{~g}^{-1}\right)\end{array}$} & 0 & $418,21 \mathrm{aA}$ & $418,21 \mathrm{aA}$ \\
\hline & 5 & $947,06 \mathrm{bA}$ & $935,95 \mathrm{bA}$ \\
\hline & 10 & $593,87 \mathrm{cA}$ & $905,26 \mathrm{cB}$ \\
\hline & 15 & $429,05 \mathrm{aA}$ & $890,00 \mathrm{cB}$ \\
\hline \multirow{4}{*}{$\begin{array}{l}\text { Antocianinas Totais } \\
\left(\mathrm{mg} \text { EqCianidina3-glic } 100 \mathrm{~g}^{-1}\right)\end{array}$} & 0 & $38,94 \mathrm{aA}$ & $38,94 \mathrm{aA}$ \\
\hline & 5 & $47,52 \mathrm{bA}$ & $40,22 \mathrm{aB}$ \\
\hline & 10 & $50,73 \mathrm{bA}$ & $39,37 \mathrm{aB}$ \\
\hline & 15 & $70,09 \mathrm{cA}$ & $33,77 \mathrm{bB}$ \\
\hline \multirow{4}{*}{$\begin{array}{l}\text { Ácido Ascórbico } \\
\left(\mathrm{mg} 100 \mathrm{~g}^{-1}\right)\end{array}$} & 0 & $3,40 \mathrm{aA}$ & $3,40 \mathrm{aA}$ \\
\hline & 5 & $1,30 \mathrm{bA}$ & $3,20 \mathrm{aB}$ \\
\hline & 10 & $0,15 \mathrm{cA}$ & $1,45 \mathrm{bB}$ \\
\hline & 15 & $0,10 \mathrm{cA}$ & $1,40 \mathrm{bB}$ \\
\hline \multirow{4}{*}{$\begin{array}{l}\text { Atividade Antioxidante } \\
\left.(\mu \mathrm{mol} \mathrm{g})^{-1}\right)\end{array}$} & 0 & $24,35 \mathrm{aA}$ & $24,35 \mathrm{aA}$ \\
\hline & 5 & $35,97 \mathrm{bA}$ & $37,30 \mathrm{bA}$ \\
\hline & 10 & 24,64 aA & $39,39 \mathrm{bcB}$ \\
\hline & 15 & $26,96 \mathrm{aA}$ & $44,36 \mathrm{bcB}$ \\
\hline
\end{tabular}

*Médias não seguidas de mesma letra, minúscula na coluna ou maiúscula na linha, diferem significativamente entre si pelo teste de Tukey, a $5 \%$ de probabilidade.

No que concerne ao teor de antocianinas totais, houve aumento durante o armazenamento, como se observa na tabela 1 , sendo mais pronunciado nos frutos armazenados sob AMPA. O menor teor de antocianinas totais nos frutos armazenados sob AMPR pode ter ocorrido em razão da interferência da baixa temperatura e/ou da concentração de $\mathrm{O}_{2}$ e de $\mathrm{CO}_{2}$ na rota metabólica de produção desses compostos.

Ao longo do armazenamento dos frutos, observou-se decréscimo no teor de ácido ascórbico, 
sendo este mais acentuado nos frutos mantidos em AMPA (Figura 1C). A diminuição no teor de ácido ascórbico era esperada em razão da alta instabilidade desse composto na pós-colheita de frutos (MALGARIM et al., 2006).

A atividade antioxidante foi superior no 5o dia à AMPA, diminuindo no $10^{\circ}$ dia e aumentando no $15^{\circ}$ dia de avaliação, sendo mantidos os maiores valores nos frutos armazenados sob AMPR (Tabela 1). É possível que a refrigeração tenha auxiliado na manutenção de compostos com fortes propriedades antioxidantes, como frações específicas de compostos fenólicos e/ou outros compostos não avaliados neste estudo.

\section{CONCLUSÕES}

O tratamento com $98 \mathrm{kPa}$ de $\mathrm{N}_{2}, 100 \mathrm{ppm}$ de etileno e $3,38 \mathrm{~mL}$ de etanol absoluto $\mathrm{L}^{-1}$ são eficientes na destanização de frutos de jambolão; entretanto, somente o tratamento $98 \mathrm{kPa} \mathrm{N}$ não provocou excessivo amolecimento dos frutos. AAMPR, além de aumentar a conservabilidade dos frutos de jambolão, promove a manutenção da coloração, do teor de compostos fenólicos totais e da atividade antioxidante.

\section{REFERÊNCIAS}

ANTONIOLLI, L.R. et al. Remoção da adstringência de frutos de caquizeiro 'Giombo' sob diferentes períodos de exposição ao vapor de álcool etílico. Pesquisa Agropecuária Brasileira v.35, n.10, p.2083-2091, 2000. Disponível em: <http:// www.scielo.br/scielo.php? script $=$ sci arttext\&pid $=\mathrm{S} 0100$ 204X2000001000021 >. Acesso em: 18 jun. 2009. doi: 10.1590/ S0100-204X2000001000021.

CHITARRA, M.I.F.; CHITARRA, A.B. Pós-colheita de frutos e hortaliças: fisiologia e manuseio. Lavras: UFLA, 2005 $785 \mathrm{p}$.

EDAGI, F.K.; KLUGE, R.A. Remoção de adstringência de caqui: um enfoque bioquímico, fisiológico e tecnológico. Ciência Rural, v.39, p.585-594, 2009. Disponível em: <http://www.scielo.br/ scielo.php?script $=$ sci_arttext\&lng $=$ pt\&nrm=iso\&tlng-pt\&pid=S0103$8478200900020004 \overline{6}>$. Acesso em: 17 jun. 2009. doi: $10.1590 /$ S0103-84782009000200046.

GROVER, J.K. et al. Medicinal plants of India with anti-diabetic potential. Journal of Ethnopharmacology, v.81, p.81-100, 2002. Disponível em: <http://www.sciencedirect.com/ science?_ob=ArticleURL\&_udi=B6T8D-45H98C0$6 \&$ u s e r $=686487 \& \quad \mathrm{rd} \mathrm{o} \mathrm{c}=1 \& \mathrm{fm} \mathrm{t}=\&$ orig $=$ search\&_sort $=$ d $\&_{-}$docanchor $=\&$ vie $w=$ $\bar{c} \&$ searchStrId $=\overline{9} 6814662 \overline{3} \&$ rerunOrigin $=$ googl e\&_acct $=$ C $000037759 \&$ \& version $=1 \&$ \&ur 1 Version $=$ $0 \&$ userid $=686487 \& \mathrm{md} 5=4 \mathrm{~b} 98 \mathrm{~b} 8 \mathrm{e} 76 \mathrm{cb} 8 \mathrm{c} 538 \mathrm{~b} 82 \overline{\mathrm{b}} \mathrm{cbdb} 73027 \mathrm{a} 87>$ Acesso em: 10 mai. 2009. doi: 10.1016/S0378-8741(02)00076-4.

INSTITUTO ADOLFO LUTZ. Normas analíticas do Instituto Adolfo Lütz: métodos químicos para análise de alimentos. 3.ed. São Paulo: Coordenadoria dos Serviços Técnicos especializados - Secretaria do Estado de Saúde, 1985. $533 \mathrm{p}$.

LEES, D.H; FRANCIS, F.J. Standardization of pigment analyses in cranberries. HortScience, v.7, n.1, p.83-84, 1972.

LIMA, L.A. et al. Correlation of anti-inflammatory activity with phenolic content in the leaves of Syzygium cumini (L.) skeels (Myrtaceae). Quimica Nova, v.30, n.4, p.860-864, 2007. Disponível em: <http:/www.scielo.br/scielo.php?pid=S010040422007000400019\&script=sci_arttext $>$. Acesso em: 12 mai. 2009. doi: $10.1590 / \mathrm{S} 0100-40422007000400019$.

MALGARIM, M.B. et al. Sistemas e condições de colheita e armazenamento na qualidade de morangos cv. camarosa. Revista Brasileira de Fruticultura, v.28, p.185-189, 2006. Disponível em: <http://www.scielo.br/pdf/rbf/v28n2/ a07v28n2.pdf>. Acesso em: 21 mai. 2009. doi: 10.1590/ S0100-29452006000200007.

RE, R. et al. Antioxidant activity applying an improved ABTS radical cation decolorization assay. Free Radical Biology and Medicine, v.26, p.1231-1237, 1999. Disponível em: $<\mathrm{ht} \mathrm{t} p: / / \mathrm{w}$ w w. s c i e n c e d i r e c t c o m/ science?_ob=ArticleURL\&_udi=B6T38-3 WM5D19R\& user $=686487 \&$ coverDate $=05 \% 2$ F 3 1\%2F 1999 \&_alid $=968141942 \&$ \& rdoc $=1 \&$ \&mt $=$ high \&_orig $=$ search \& $\mathrm{cdi}=4940 \&$ sort $=\mathrm{r} \&$ docanchor $=\&$ view $=\mathrm{c} \& \mathrm{ct}=26 \&$ a $\mathrm{cct}=\mathrm{C} 000037759 \&$ version $=1 \&$ urlVersion $=0 \&$ userid $=6864 \overline{87}$ $\& \mathrm{md} 5=6 \mathrm{fb} 13674 \mathrm{f} 4178 \mathrm{~cd} 1 \mathrm{ee} 6 \overline{2} 28 \mathrm{f} 28951318 \mathrm{c}>$. Acesso em 25 mai. 2009. doi:10.1016/j.freeradbiomed.2009.05.039.

REYNERTSON, K.A. et al. Quantitative analysis of antiradical phenolic constituents from fourteen edible Myrtaceae fruits. Food Chemistry, v.109, p.883-890, 2008. Disponível em: $<\mathrm{ht} \mathrm{t}$ p:// w w w s c i e n c e d i r e c t c o m/ science? ob=ArticleURL\& udi=B6T6R-4RMNYM1$9 \&$ \& us e $\bar{r}=686487 \&$ rdo $=1 \&$ \&m t $=\&$ _orig $=$ se $\operatorname{arch} \&$ sort $=\mathrm{d} \&$ docanchor $=\&$ view $=\mathrm{c} \&$ searchStrId $=9$ $68140363 \&$ rerunOrigin $=$ google \& acct $=$ C 0000377 $59 \&$ \&ersion $=1 \&$ \&urlVersion $=0 \&$ \& userid $=686487$ $\& \mathrm{md} \overline{5}=71 \mathrm{~d} 22272 \mathrm{e} 5 \mathrm{ae} \bar{b} 3 \mathrm{bfc} 1946 \mathrm{fb} 4 \mathrm{~b} 1 \mathrm{a} 985 \mathrm{a} 4>$. Acesso em 25 mai. 2009. doi: 10.1016/j.foodchem.2008.01.021

SALVADOR, A. et al. Reduction of chilling injury symptoms in persimmon fruit cv.Rojo Brillante by 1 -MCP. Postharvest Biology and Technology, v.33, p.285-291, 2004. Disponível em: <http://www.sciencedirect.com/ science? ob=ArticleURL\& udi=B6TBJ-4CTN60V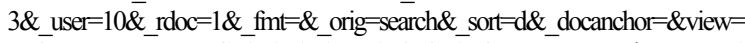

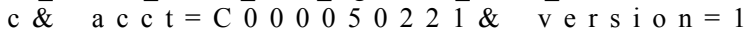
\&_urlVersion=0\&_userid $=10 \& m d 5=2 \mathrm{a} 6 \mathrm{~b} 02 \mathrm{~d} 6 \mathrm{~b} 87 \mathrm{c} 788 \mathrm{c} 7 \mathrm{a} 83399 \mathrm{~d} 2 \mathrm{~b} 3 \mathrm{ea} 85 \mathrm{~d}>$. Acesso em: 24 jun. 2009. doi:10.1016/ j.postharvbio.2004.03.005.

SALVADOR, A. et al. Reduced effectiveness of the treatment for removing astringency in persimmon fruit when stored at $15^{\circ} \mathrm{C}$ : Physiological and microstructural study. Postharvest Biology and Technology, v.49, p.340-347, 2008. Disponível em: <http://www.sciencedirect.com/ science? ob=ArticleURL\& udi=B6TBJ-4SM206M$1 \&$ _user $=\overline{6} 86487 \&$ rdoc $=1 \&$ fmt $=\&$ \&orig $=$ search $\&$ _sort $=\mathrm{d}$ $\& \overline{\text { docanchor }}=\& \mathrm{view}=\mathrm{c} \&$ searchStrI $\mathrm{d}=968137952 \&$ reru nOrigin $=$ google\&_acct $=\bar{C} 000037759 \&$ version $=1 \&$ u r 1 Ve r s ion $=0 \&_{-}$u s e r i d $=6864 \overline{8} 7 \&$ m d $5=\overline{8}$ e 70ce2d28d199a8970b46f4dda999f9>. Acesso em: 24 mai. 2009. doi: 10.1016/j.postharvbio.2008.01.015. 
SINGLETON, V.L.; ROSSI, J.A. Jr. Colorimetry of total phenolic with phosphomolybdic-phosphotungstic acid reagents. American Journal of Enology and Viticulture, v.16, p.144-158, 1965. Disponível em: <http://www.ajevonline.org/ cgi/content/abstract/16/3/144>. Acesso em: 12 abr. 2008.

VEIGAS, J.M. et al. Chemical nature, stability and bioefficacies of anthocyanins from fruit peel of syzygium cumini Skeels. Food Chemistry, v.105, p.619-627, 2007. Disponível em: <http:// www.sciencedirect.com/science?_ob=ArticleURL\&_udi=B6T6R4 NKJ 0 MM - 5\&_user $=686487 \&$ rdoc $=1 \&$ fm t $=\&$ _orig=search $\&$ _sort $=$ d \&_d o c a n chor $=\&$ view $=\mathrm{c} \& \quad \mathrm{~s}$ e a r c h Str I $=968136377 \&$ re r u nOrigin $=$ google \&_a c c t $=$ C $000037759 \&_{-}$_vers i o $n=1 \&$ url Vers i o $n=0 \& \quad$ us e rid $=686487$ $\& \mathrm{md} 5=6910 \overline{6} \mathrm{e} 989 \mathrm{db} 4 \mathrm{bc} 46 \mathrm{be} 0 \mathrm{fc} 641 \mathrm{af} 303 \mathrm{e} 95>$. Acesso em: 22 mai. 2009. doi: 10.1016/j.foodchem.2007.04.022.
VINCI, G. et al. Ascorbic acid in fruits: a liquid chromatographic investigation. Food Chemistry, v.53, p.211-214, 1995. Disponível em: <http://www.sciencedirect.com/ science?_ob=ArticleURL\&_udi=B6T6R-3 YYT67V$1 \mathrm{~T} \&$ _user $=686487 \&$ _rdoc $=1 \&$ fmt $=\&$ \&orig $=$ search $\&$ _sort $=$ d\&_docanchor $=\&$ view $=$ c\&_searchStrId $=968135278$ $\&$ \&erunOrigin $=$ google \&_acct $=$ C $000037759 \&$ _ version $=1 \&$ _ur 1 Version $=0 \&$ \& us erid $=6864$ $87 \& \mathrm{md} 5=\mathrm{f} 771929 \mathrm{c} 5 \mathrm{c} 099 \mathrm{fd} 6396 \mathrm{f} 8 \mathrm{bbf} 10437240>$. Acesso em: 21 abr. 2008. doi: 10.1016/0308-8146(95)90791-5.

VIZZOTTO, M.; PEREIRA, M.C. Caracterização das propriedades funcionais de jambolão. Pelotas: Embrapa Clima Temperado, 2008. 26p. (Boletim de Desenvolvimento e Pesquisa). 